\title{
Scaling Up to Networks of Marine Protected Areas in the Philippines: Biophysical, Legal, Institutional, and Social Considerations
}

\author{
G. K. LOWRY, ${ }^{1}$ A. T. WHITE, ${ }^{2}$ AND P. CHRISTIE ${ }^{3}$ \\ ${ }^{1}$ Department of Urban and Regional Planning, University of Hawaii at Manoa, \\ Honolulu, Hawaii, USA \\ ${ }^{2}$ Global Marine Team, The Nature Conservancy, Honolulu, Hawaii, USA \\ ${ }^{3}$ School of Marine Affairs and Henry M. Jackson School of International Studies, \\ University of Washington, Seattle, Washington, USA
}

\begin{abstract}
The growing number of marine protected areas (MPAs) globally represents an increasing interest in marine conservation and fisheries management and the potential of planned and managed MPA networks as a way of strengthening local management. This study documents the development of MPA networks in the Philippines and identifies critical success factors and issues. Methods were field observation by participation in MPA and fisheries management projects and focused interviews that gathered opinions and observations of primary MPA network stakeholders in the central Visayas region. Findings show that an MPA network is defined through social and ecological criteria. From a social perspective, a network is comprised of people and organizations that manage component MPAs, benefit from the network, and promote the network's viability through shared administrative responsibility and information. To qualify as part of an ecological network, individual MPAs must interact ecologically (e.g., source or sink of larvae and propagating organisms, protection for habitat, and threatened or endangered species) to enhance fisheries and biodiversity conservation. The study found that while social and ecological criteria are shaping MPA networks through science-based planning, integrated management, and coordination, there exist numerous institutional issues related to scaling up to networks from single MPAs. Issues pertain to: limiting access to resources, boundary delineation, monitoring compliance, finding common goals and identity, and conflict resolution. Factors correlated with management success included common institutional processes and legal support, improved understanding of benefits from a network and improved habitat conditions and fishery yields associated with MPAs.
\end{abstract}

Keywords institutions, marine conservation, MPA, MPA network, protected areas

\section{Introduction to Philippine MPAs and MPA Network Development}

The role that marine protected areas (MPAs) play in promoting ocean and coastal health is increasingly recognized by leading conservation organizations and leaders: The World Summit on Sustainable Development, the IUCN's World Commission on Protected Areas, the Convention on Biological Diversity, and the G8 Group of Nations (WCPA/IUCN, 2008;

Address correspondence to G. K. Lowry, Department of Urban and Regional Planning, Saunders Hall 107, University of Hawaii at Manoa, Honolulu, Hawaii 96822, USA. E-mail: lowry@ hawaii.edu 
UNEP/WCMC, 2008). There is also a growing recognition that MPAs must be planned and implemented as a network to maximize conservation and fisheries management objectives (World Bank, 2006; IUCN-WCPA, 2008). To meet the ambitious global targets for MPAs the Philippines must allocate resources and leadership to the development and management of MPAs so that 20-30\% of critical habitat is within the confines of a MPA by 2012 (WCPA/IUCN, 2007). Because the Philippines lies in the area of highest marine biodiversity in the world (Carpenter \& Springer, 2005), its marine conservation efforts are crucial to the protection of global biodiversity.

In response, the Philippines has established approximately 1,100 MPAs through innovative approaches and devolution of responsibility to local governments that cover approximately $15,000 \mathrm{~km}^{2}$ (White et al., 2002; PhilReefs, 2008). These are comprised of 26 nationally designated MPAs with the remainder under local government designations (WFC, 2007). A management effectiveness and rating system for MPAs that was recently established suggests that about $20 \%$ of these MPAs are achieving their management objectives (White et al., 2006a). The primary objective for the establishment of MPAs since the early 1980s has been to enhance coral reef fisheries. This occurs through habitat protection and the improved ability of reef fishes to grow to mature sizes for enhanced reproduction and spill over of larvae and adult fishes to adjacent areas outside of no-take zones within an MPA in some cases (Russ et al., 2004; Evans et al., 2008). Additional benefits recognized as equally important for local stakeholders include enhanced livelihood opportunities from tourism and related economic activities associated with an MPA (White et al., 2006a and b; IUCN-WCPA, 2008).

Recent studies show that MPAs in the Philippines are generally more effective when implemented within the context of an integrated coastal management (ICM) regime through the local government system in the country (Balgos, 2005; White et al., 2002; 2005; IUCNWCPA, 2008). Factors affecting success within such ICM include enhanced fisheries management outside of the MPA and better control of other stresses (Christie et al., 2002). Networking among people and integration of ecosystem-based management within various governance hierarchies is also being initiated, which supports MPA implementation. Thus, to meet the continuing challenges of coastal degradation, all levels of government and the private sector are engaging to coordinate with each other through ICM, fisheries management, and networking arrangements.

Factors important for scaling up to functional and effective MPA networks (ecological and institutional) are the focus of this article. The analysis centers on the development of MPA networks from a legal, social, institutional, and practical management perspective while considering what principles are most important in assuring that the biophysical and ecological criteria for good network design are addressed. Experience from the Danajon Bank area of northern Bohol Island and southern Cebu Island, central Philippines is highlighted where MPAs have been designated in years past and are now being managed from a network perspective to enhance fisheries management and biodiversity conservation (Armada et al., 2009; Christie et al., 2009; Eisma-Osorio et al., 2009).

\section{Rationale for MPA Networks in the Philippines}

MPA networks are now being promoted as a means to enhance fisheries management and biodiversity conservation beyond what individual MPAs can achieve as evidenced in recent reviews (Palumbi, 2004; IUCN-WCPA, 2008). Given this desire to "scale up" to MPA networks to achieve these benefits, the Philippines is trying to improve its management of fisheries through the implementation of MPAs and networks. An immediate objective to 
enhance fisheries is to improve the management and enforcement of existing MPAs and to increase the area of coastal and fisheries habitat that is protected.

Two or more MPAs that complement each other can form a "network." Ecological networks are formed when the natural connections between and within sites enhance ecological functions and benefits of one or more MPAs become the rationale for management. In order to enhance the administration and management of ecological networks, social networks are being formed through communication and sharing of results and coordination among institutions. Both types of network, social and ecological, are being developed in order to optimize the benefits of a more holistic systems approach (Pietri et al., 2009; White et al., 2006a).

Given these priorities of fisheries management and biodiversity conservation, MPAs and MPA networks are being designed in the Philippines based on the following considerations (WCPA/IUCN, 2007; Roberts et al., 2003; Russ et al., 2004):

- Biogeographic and habitat representation;

- Presence of species or populations of special interest;

- Size of reserves necessary to protect viable habitats;

- Presence of exploitable (target) species;

- Vulnerable life stages of selected species;

- Connectivity among reserves and links among ecosystems; and,

- Provision of ecosystem services to people.

Another rationale for emphasizing the development of MPA networks is that the investment in the establishment and management of the MPA network better maximizes its potential return to local stakeholders (IUCN-WCPA, 2008). In forming a network, it is also possible to create a biophysical information base for the MPAs in order to make science-based management decisions. Finally, a network provides a rationale for individual MPA stakeholders or communities to coordinate with each other to share their experiences and resources, and to enhance efforts in protecting their respective MPAs.

Biogeographic sub-regions based on reef species diversity and affinities are being used as a means to determine boundaries for MPA networks as shown in Figure 1. A broad starting point for the MPA system design in the Philippines is the context of the linkages of geomorphology of the basins and the role of bottom topography in ocean circulation among basins. The positions of the major marine corridors are found in the transition areas of the major biogeographic regions or inland sea basins. Along these areas are found critical nesting, nursery, and feeding grounds for important marine species. Connectivity of ecosystems as facilitated by marine corridors is a criterion to facilitate network linkages among priority biogeographic areas and is being used in the Philippine context for planning (Ong et al., 2002; White et al., 2006a).

\section{MPA Networks in the Philippines}

There are nested levels of jurisdictions from small village to multiple municipal levels and national that must be considered in developing effective MPA networks in the Philippines (Eisma et al., 2005; Lowry et al., 2005). Although there is an understanding of needs at a national and international scale as noted earlier, the active network design and implementation work is being done at the sub-national level. The starting point has been social, institutional and learning networks. If the individual site has fisheries and social economic values associated with it, the likelihood of good management appears to be enhanced (Pomeroy et al., 2005; Pollnac \& Pomeroy, 2005; White et al., 2006a). 


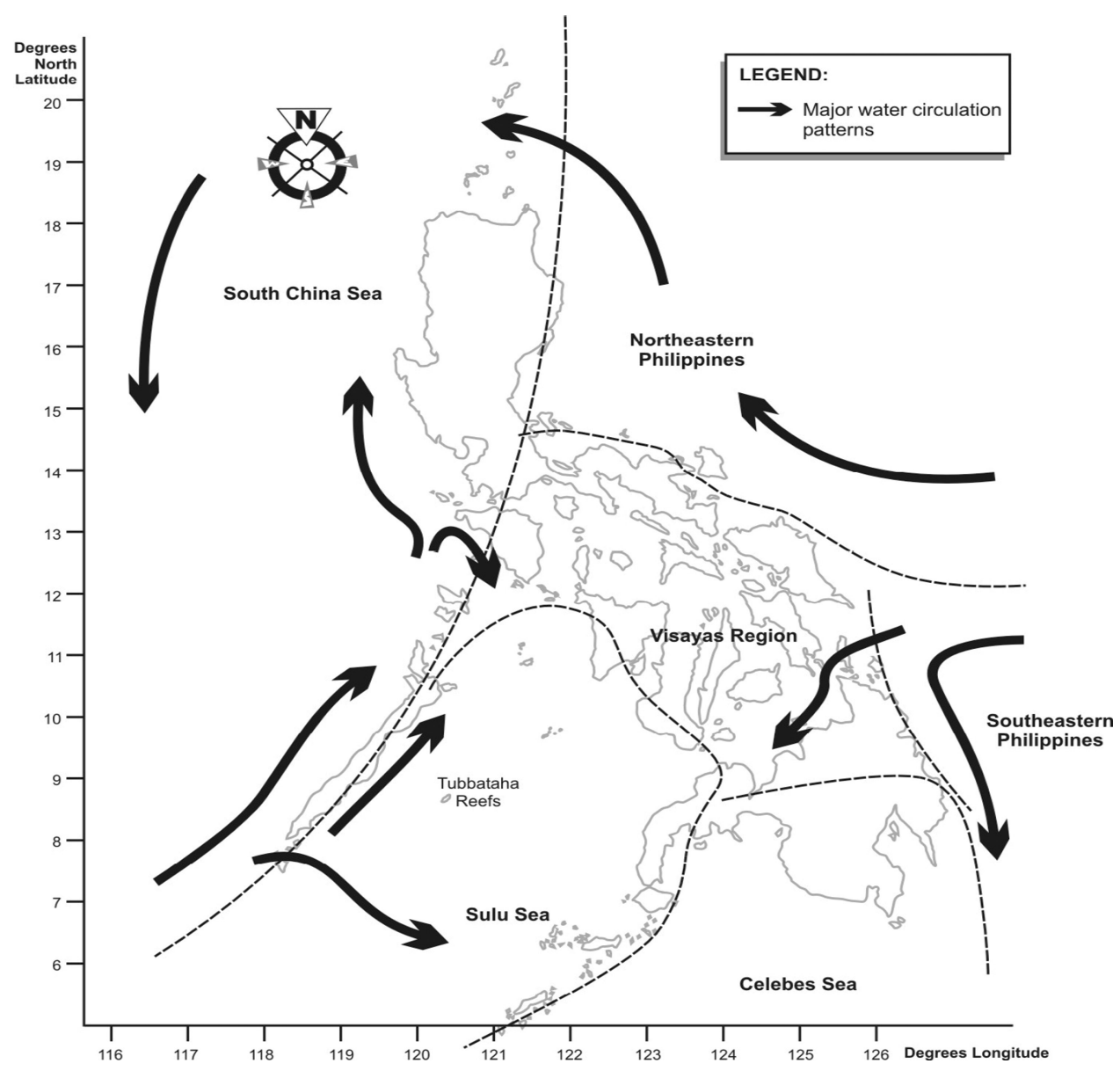

Figure 1. Philippine biogeographic areas important for marine conservation planning based on geomorphology, basins, bathymetry, species affinities, and water circulation patterns (Alino et al., 2002).

MPA networks are being formed in the Philippines that combine ecological, institutional, and social criteria and functions. MPA networks in the Central Visayas at Danajon Bank and South Cebu are being designed in ways that incorporate ecological and social functions through active planning and management (Table 1). In addition to these placebased, ecological, and social networks, marine associated communities in the Philippines are forming and sharing information and experiences through newsletters, e-mail, and a growing list of loose organizations that form learning "networks." One locally based network that seems to be effective is the national alliance of community-based MPA managers, the PAMANA Ka Sa Pilipinas Inc., composed of local representatives of municipal marine sanctuaries (Lavides \& Tiburcio, 2002) (Table 1).

The formation of the MPA network in Danajon Bank of Bohol Island is motivated by benefits to fishers derived from spillover, larval recruitment, and protection of reproductive potential as well as financial and administrative benefits. Here the benefits derived from sustained management inside no-take areas and the surrounding effects (benefits) outside the no-take areas, where illegal fishing is usually stopped, are driving adaptive management 
Table 1

Selected active coastal and marine related networks and primary concerns

\begin{tabular}{|c|c|}
\hline Type or name of network/organization & Primary concerns or mandate \\
\hline $\begin{array}{l}\text { Danajon Bank MPA Network, northern } \\
\text { Bohol Island }\end{array}$ & $\begin{array}{l}\text { Group of local governments and community } \\
\text { groups that aspire to develop and maintain a } \\
\text { network of functional MPAs to enhance } \\
\text { fisheries and protect critical habitat in the } \\
\text { Danajon Bank double barrier reef in north } \\
\text { Bohol Island, Visayas }\end{array}$ \\
\hline South Cebu MPA Network & $\begin{array}{l}\text { Group of local governments and community } \\
\text { groups that aspire to develop and maintain a } \\
\text { network of functional MPAs to enhance } \\
\text { fisheries, protect critical reef and mangrove } \\
\text { habitat, and enhance tourism revenues in } \\
\text { southern Cebu Island }\end{array}$ \\
\hline $\begin{array}{l}\text { National MPA Support Network } \\
\text { (MSN) }\end{array}$ & $\begin{array}{l}\text { National network of MPA managers, advocates, } \\
\text { and practitioners composed of } 27 \text { national and } \\
\text { regional government agencies, academic } \\
\text { institutions, and NGOs }\end{array}$ \\
\hline $\begin{array}{l}\text { Locally Managed Marine Area } \\
\text { (LMMA) Network }\end{array}$ & $\begin{array}{l}\text { International network of local marine managed } \\
\text { areas with a national affiliation and several } \\
\text { project areas. LMMA has a community-based } \\
\text { approach and links with other local and } \\
\text { national MPA networks }\end{array}$ \\
\hline PAMANA Ka Sa Pilipinas Inc. & $\begin{array}{l}\text { MPA network for community-based } \\
\text { practitioners both private and government, has } \\
\text { about } 120 \text { member sanctuary sites }\end{array}$ \\
\hline $\begin{array}{l}\text { Philippine Coral Reef Information } \\
\text { Network (PhilReefs) }\end{array}$ & $\begin{array}{l}\text { National information sharing among academic } \\
\text { groups concerned with reefs }\end{array}$ \\
\hline
\end{tabular}

arrangements. Monitoring of the biophysical, social, and economic outcomes of MPAs in the Danajon Bank is providing feedback to demonstrate the impacts of good stewardship and at the same time helping create buy-in that promotes public-private partnerships. Recognition awards are assisting to build network-level commitment in Danajon (Armada et al., 2009).

The Danajon Bank MPA network is being institutionalized through provincial and municipal task forces for fisheries law enforcement within the context of a larger ICM program that includes good governance practices. Attention to performance monitoring and impact assessment is promoting sustainable management and encouraging the participation of all stakeholders (Figure 2).

A major challenge in the implementation of the network in Danajon is the action required by local governments to sustain network efforts. The improvement of local fisheries can capture the imagination and commitment of separate management bodies to work together at the larger network scale. This requires sharing of results from assessments and showing overlays of habitat maps with the important spawning events and areas together with their fishing practices to plan for management of key areas. Plans must include habitat 


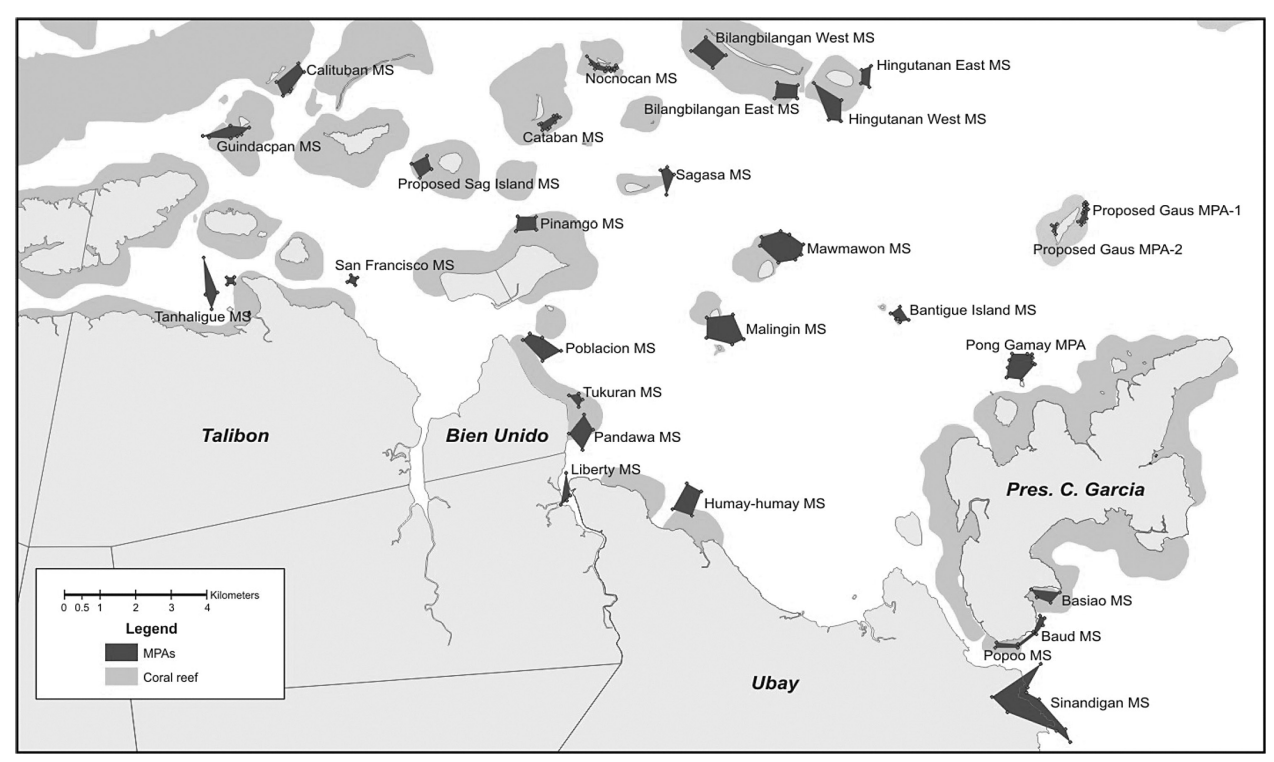

Figure 2. No-take MPAs established in the Danajon Bank are beginning to form a network.

maps, sensitive areas subject to greatest threats that require protection, and combined enforcement areas that lead to joint inter-local government ordinances or common provincial action plans (Indab \& Aspilla, 2004).

Local communities that have endorsed the stewardship of their marine sanctuaries are encouraged if they see the linkage of their village life with that of their ecosystem stewardship role at a larger scale (Christie et al., 2003). The larger scale demonstration of entrainment potential, connectivity, and spawning aggregation applies at both the local village scale and the larger ecosystem and eco-region scales. The establishment of a combination of village level MPAs in combination with municipal and multi-municipal- level management is crucial to create synergistic benefits.

Given the importance of fisheries in the Philippines, planning teams must consider factors that maximize the fisheries value of a MPA. Criteria used that weigh decisions toward areas with more potential for fisheries enhancement and that are practical to implement include (White et al., 2006a):

- Habitat quality: Areas with superior habitat quality or relatively better than the average for the general area (e.g., coral cover, seagrass, water quality);

- Fish habitat: Areas that maintain higher than average abundance, density, and species richness of fishes or contain spawning aggregations of fish;

- Oceanography: Areas with favorable currents that tend to aggregate larvae and organisms inside the sanctuary but with periodic flushing to the outside;

- Biodiversity: Areas with higher than average biodiversity and range of animals on the food chain from large to small;

- Size: Areas that cover at least 20 hectares of critical fisheries habitat;

- Social acceptance: Areas that will not arbitrarily remove the most desired fishing ground from a community and do not create unnecessary conflicts;

- Practicality of management: Areas where no fishing and extraction can be enforced given the resources that will be available for protection; and, 
- Quality of management: Areas that can achieve MPA rating system ${ }^{1}$ level 3 where the rules are sufficiently enforced to ensure tangible fisheries benefits.

These criteria are being applied to provide relative assurance that a single MPA will contribute significantly to fisheries enhancement. At the same time, areas with optimal habitat and oceanographic qualities will often be a favored fishing area. Thus, while managers try to apply the aforementioned criteria they realize that there are tradeoffs between what is ideal versus what is practical and that to fully apply all criteria is often not possible (Jones, 2007). Additional attributes needed to create functional MPA networks with a balance between social and environmental dimensions include (PhilReefs, 2008):

- Individual MPAs meet minimum criteria for MPAs in general and managed at MPA rating level 3 or more;

- The management area analyzed from the perspective of critical habitats, fisheries, oceanography, and including existing MPAs as a first step in planning an area-wide network;

- Site specific areas (multi-municipal to barangay level) analyzed from perspective of critical habitats, fisheries, oceanography, and including existing MPAs as a second step in detailed planning for MPA priority sites and networks;

- Existing MPAs and new sites that maximize fisheries enhancement are identified;

- Five to 20 percent of critical habitat for a given planning area is within an MPA;

- MPA management bodies will be capacitated to improve the management of their MPA and linked to other MPA management bodies in the network area;

- MPA management bodies together with local governments and other assisting organizations are engaged in planning and implementing their MPA network; and;

- A MPA network will be incorporated in ICM plans and regimes of one or more municipal governments with provincial assistance.

In summary, the basic attributes of MPA networks being developed in the Philippines as shown in Figure 3 include MPAs that are effective in their own right, protect fisheries habitats, and enhance fisheries, following the aforementioned criteria. A goal is for MPAs to cover a critical minimum area (e.g., 5 to $10 \%$ ) of the larger planning area. MPA management bodies must be effective and linked to the larger planning area through a network of sorts. Thus, management needs to include institutions at the local level as well as national institutions for integration and sustainability. Local governments are playing key roles with supporting partners.

\section{Ecological Challenges in Network Design and Implementation}

Careful network design based on ecological principles requires (Palumbi, 2004; Roberts et al., 2003; Palumbi, 2004):

- Connections of adjacent or continuous habitats such as coral reefs and sea grass beds;

- Connections through regular larval movement in the water column between and within the MPA sites;

- Dispersal of some of the larval from a given MPA will either end up settling back inside the MPA or in a MPA within the dispersal range or spatial neighborhood of the typical species residing in the MPA; 


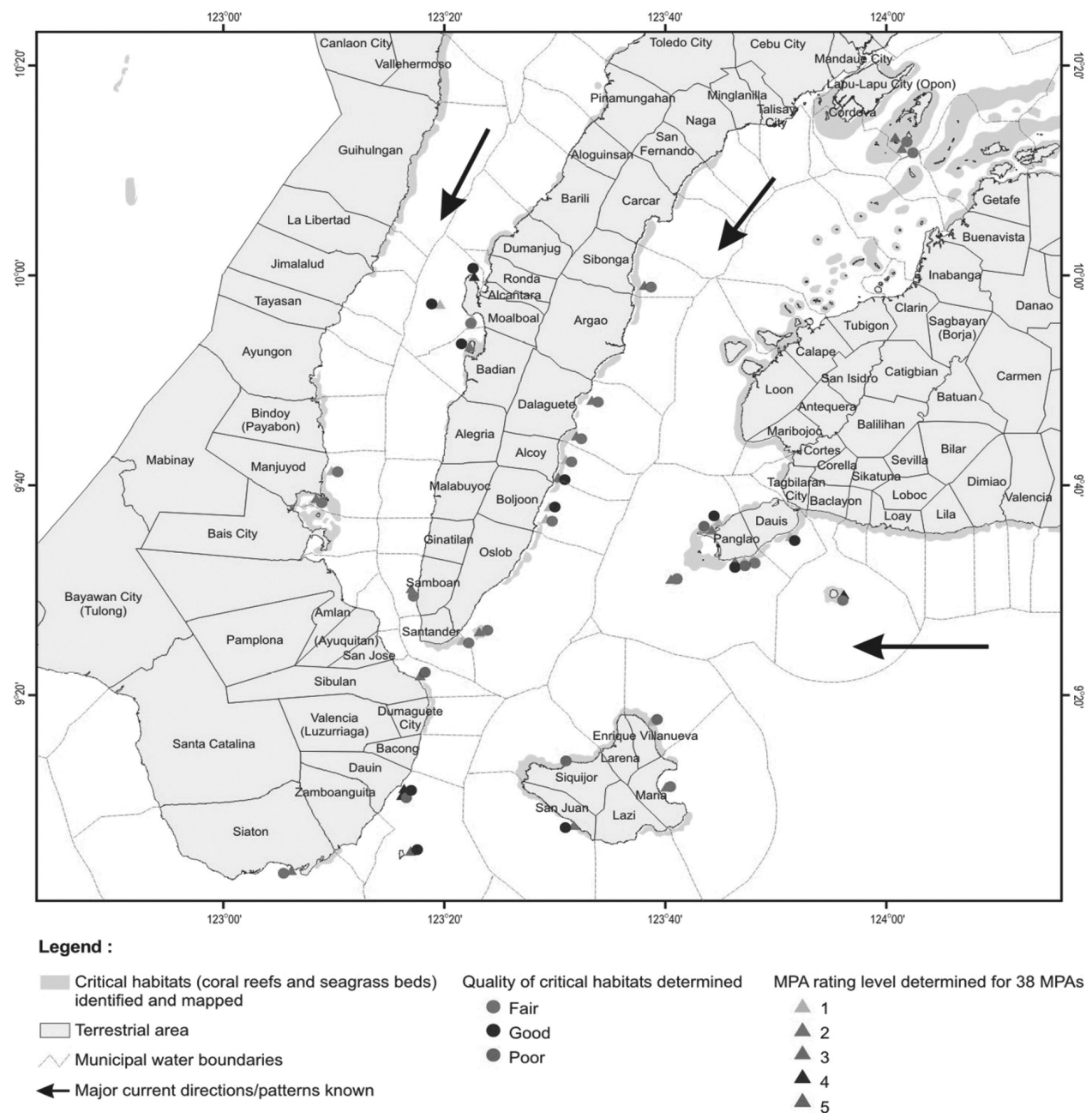

Figure 3. Area under municipal jurisdiction with a functional MPA network.

- Movement of mature marine life from one site to another depending on habitats or because of regular or random spillover effects from MPAs;

- Partial protection of the most valuable marine habitats as reflected by habitat quality and species richness;

- Adequate habitat space to reproduce and disperse larvae into surrounding areas for threatened, vulnerable or over-exploited species of a given area; (e.g., giant clams, grouper, lobsters); and,

- Planning to benefit of both fisheries and conservation to ensure larval production and dispersal and fish spillover effects are maximized.

Planning ideal ecological MPA networks is much easier than realizing them given constraints in implementation. The Philippine MPA networks in Danajon Bank and south Cebu have been developed from MPAs that were not originally planned as a network. Thus, the current "networking" is occurring retroactively to determine connectivity and the degree to which sufficient habitat area has been included within the MPA network. One limitation 
in this process is that some of the original MPAs may not be in an optimal location to contribute fully to the network. However, because it is not feasible or politically wise to remove existing MPAs, the planning process must be more attentive to the location and linkages among new MPAs.

Another issue is the size of the MPAs. Most of the municipal-based MPAs are in the size range of 10 to 100 hectares. While this size is sufficient to protect habitat and to build up biomass of marine life, it is not sufficient for much self recruitment to occur or for life stages of marine species to be fully protected. Pelagic fish species will regularly move beyond boundaries. Although size is generally not sufficient among these small MPAs, the benefits achieved through a network of small MPAs is still substantial in the eyes of the local stakeholders. These benefits are being measured in terms of improved habitat quality, increased fish biomass inside no-take zones, and spillover of adult fish to fished areas outside of no-take areas (Russ et al., 2004).

The challenge of scaling up to MPA networks in the Philippines in a manner that addresses the list of aforementioned ecological criteria is also inhibited by a lack of ability to gather all the information required to design an ecological network. Measuring connectivity among sites is not simple and requires an investment in scientific expertise and equipment that is not usually available. The exception to this, as in the Danajon Bank and now in south Cebu, is when an externally funded project supports the research required to gather the basic information needed to plan and develop a MPA network.

\section{Institutional Issues in MPA Network Design and Implementation}

In light of the ecological linkages among MPAs, some resource managers have sought to design governance arrangements that extend beyond the management of individual MPAs. In particular, the concept of "network governance" has been promoted as a management framework for linking multiple MPAs. Networks are "both a governance structure and a process of socialization through which disparate actors and organizations are connected in a coherent manner for mutual benefits and synergies" (Yeung, 2000). Networks vary in the purposes and in the degree of formality and complexity. Many networks are informal associations based on shared interests, issues, or tasks. A few networks operate more formally with membership requirements, an explicit agenda, and detailed governance arrangements.

Designing individual MPAs and MPA networks requires particular attention to institutional issues in addition to ecological design criteria. At present, most Philippine MPAs are small, community-managed efforts. There are also examples of local co-managed MPAs in which local governments are involved and management is primarily by a single government agency or in collaboration with a nongovernmental organization together with local stakeholders.

Because ocean areas in the Philippines are almost always under open access property regimes with little control over resource user movement or fishing effort, successful MPA management requires at a minimum: (1) the ability to limit access or exclude some resource users and (2) control over the amount and timing of resource extraction by authorized users. The development of institutions - ordinances, rules, or norms - governing access and resource appropriation represent the basic tasks of governance of MPAs.

Community-based management assumes that the community [or a group within the community] has sufficient capacity [knowledge, organizational ability, mutual trust, etc.] to develop rules or norms to govern their own use of resources. Such rules are based on the expectation that limiting resource extraction in the short-run will result in increased resources at a future time. 
In practice, designing effective institutions for community management requires addressing several challenges. The first is the potential social, cultural, and economic complexity of many communities. The notion of community-based management suggests a homogeneous community with shared interests-or at least the possibility of developing shared interests as a basis for resource governance. In practice, communities, even small rural ones, are rarely homogeneous. Different class, caste, gender, ethnic, or family divisions may impede a shared sense of community vision or purpose (Davis \& Bailey, 1996; Agrawal \& Gibson, 1999). More powerful groups may sometimes dominate local institutional development - and the control of access to resources.

Forces external to the community may also influence community-level institutional performance. Powerful outsiders may be able to extract resources from MPAs without fear of effective retaliation. Environmental threats such as discharges from industrial plants, quarrying activities, mangrove clearing, or other coastal development near the MPA may stress the habitat.

Matching institutional boundaries with resource boundaries is another challenge (Berkes, 2006). MPAs are often part of larger ecological systems, as noted earlier. Management of individual sites may overlook the importance of larval production and dispersal that may involve multiple MPAs. A forestry management agency may exercise jurisdiction over resource uses such as mangrove clearing that have direct impacts on nearby reefs.

The institutional challenges posed by community heterogeneity, threats from outside, and lack of "fit" between institutions and resource systems are being addressed in a variety of ways. Greater attention to community attributes when developing MPA management institutions, more emphasis on the potential of co-management among communities and local government resource management agencies, increased focus on managing at different resource scales, and developing institutions that are sensitive to issue of scale and comanagement are central institutional development concerns (Imperial \& Yandle, 2005; Berkes, 2006; Folke et al., 1998).

This section focuses on a major institutional development issue in the context of "scaling up" to network management in the Philippines: What are the primary institutional issues associated with MPA network governance? What is the Philippine experience in addressing these institutional issues?

\section{Coordination}

A network of MPAs, formed on the basis of ecological linkages, necessarily implies a somewhat larger geographical area that incorporates individual MPAs and the spaces between them. This larger geographic area requires management over marine areas-and resource uses in those areas - that may affect individual MPAs, but may be beyond the management capacity of particular communities engaged in management of existing MPAs. Management of these larger areas requires both coordination among the managers of existing MPAs and coordination with local and provincial units of government responsible for management of coastal development, fisheries, and mangroves and other habitats.

Coordination, in this context, may involve sharing information among MPA managers about particular resource threats, sharing knowledge, mobilizing resources for better enforcement, organizing training activities that benefit multiple communities, and a host of other activities. It may also involve working with Local Government Units to encourage closer monitoring and enforcement of violations of the fisheries regulations around MPAs or seeking resources for improving community management capacity. 
Such coordination can occur through a variety of formal and informal institutions. In the case of Southwest Cebu, MPAs have been established in the eight municipalities. Currently, there are 22 MPAs with no-take areas covering $0.24 \%$ of the total combined municipal waters. These MPAs are mostly managed by fisher's organizations in coordination with the municipal governments (Eisma-Osorio et al., 2009):

A coordinating body for all identified programs of the eight municipalities was formed through the Southeast Cebu Coastal Resource Management Council. It is composed of Mayors and Vice-Mayors of eight municipalities and functions as a policy-making and supervising body. A complete set of officers led by a Chairman is elected among the Vice-Mayors of the municipalities who shall hold their positions for three years co-terminus to their term of office as elected officials.

To assist the Council, a management committee and a secretariat, composed mostly of technical staff from each municipality, was organized. In addition, a technical and legal advisory group coming from government agencies such as the Department of Environment and Natural Resources, BFAR, and Philippine National Police, as well as NGOs such as the Environmental Legal Assistance Center and the CCEF, provide specialized support to the Council. The Council often calls on any of these government agencies and/or NGOs for technical inputs, legal advice, logistical support, and other forms of technical assistance. The management committee headed by an Executive Director administers the day-to-day activities of the Council while the secretariat serves as the record keeper and financial manager. Both the management committee and secretariat have provided an effective coordination and feedback mechanism to the respective municipalities.

The Council, although still young and evolving, has become a venue for the discussion and resolution of important issues and activities, such as the banning of compressor fishing; protection of critical habitats from foreshore development; the reduction of fishing effort through fisherfolk, fishing gears and boat registration, regulating controversial and destructive fishing gear (e.g. modified drift gill nets), and strict enforcement against intrusion of commercial fishing into municipal waters; considering other externalities such as the oil seismic surveys along Cebu Strait; regulating municipal tourism activities; and creating social networks among MPA managers. It has also re-energized earlier municipal coastal management initiatives with MPAs now effectively managed, municipal seaborne and coastal law enforcers (MUSCLE) formally organized with an institutionalized incentive scheme, and with over 30 commercial fishing violators apprehended during joint law enforcement operations in April 2005.

(Eisma-Osorio et al., 2009, 298-299)

The Council in Southwest Cebu is only one possible mechanism for raising management concerns, identifying strategies for resolving shared management problems, mobilizing management resources and resolving management conflicts. Joint committees, inter-agency task forces, and memorandum of agreements are among the formal strategies for facilitating coordination of management efforts.

While coordination among MPA management teams may be useful for purposes of sharing information, coordination with local and provincial units of government can be important for improving enforcement activities, protecting habitats, and generating increased resources. Such "co-management" also involves important challenges. Co-management 
with local government, provincial fisheries offices, provincial forestry offices for mangrove management, and other agencies involves multiple actors, some of whom have different management interests and priorities. Generating common management priorities among agencies may be long and complicated (Cash et al., 2006). Hence, coordination via co-management involves more than formal agreements. Prolonged engagement among community-level managers and between community managers and agency personnel may be required before successful institutions for coordination can be developed.

\section{Learning}

Effective management of individual MPA sites or of MPA networks requires knowledge and skills. Knowledge of resource systems, how they are affected by a variety of threats such as overfishing, and the types of interventions that can reduce the impact of threats are basic to effective management. Skills in monitoring resource conditions, organizing communities, mobilizing agreement, and sustaining community commitments are also required. The processes for developing the requisite knowledge skills have varied. Occasional training of community leaders, prolonged or periodic community engagement by community organizers, and self-help manuals are all among the strategies that have been employed to build capacity for effective community and network management. All of this is to suggest that learning is critical to effective community-level management. It is even more essential for network management. With regard to network management, effective learning requires attention to multiple ecological and social processes occurring at different scales of action.

Learning has different meanings depending on whether it refers to processes involving individuals, collective agents, or wider social systems (Tabara \& Pahl-Wostl, 2007). Generally, the learning processes associated with site and network management are often referred to as "social learning" because they involve the recognition of mutual interdependencies and interactions, individual and collective analysis of cause-and-effect relationships, opportunities for critical mutual reflection among community members, and others and group deliberation and decision-making.

The Philippine MPA movement is supported by various individual and collective educational efforts. University courses in MPAs and coastal management have been established. Training efforts and manuals are commonplace. Some Internet sites (e.g., www.oneocean.org) post relevant laws, manuals, and current events and are commonly visited by Filipinos and foreigners. Cross-site visits, whereby community members and government officials visit successful MPAs, are a standard practice within educational programs. These cross-site visits have a notable inspirational influence on these participants and also allow community members to discuss the opportunities and challenges associated with MPA implementation in an informal manner.

Networks provide an opportunity for those involved in MPA management to develop the skills to monitor resource conditions on a systematic basis and to adapt management systems. Some management teams have developed protocols for exchanging information about resource conditions, best management practices, and shared management issues. Others, such as the MPA Support Network, Pamana Ka, and the Locally-Managed Marine Area network (LMMA) hold workshops, organize trainings, and even have formal data collection protocols.

\section{Observations on Processes for Building Sustainable MPA Networks}

The process of scaling up to effectively managed networks is evolving in the Philippines. The basic approach to improving the management of MPAs, identifying and planning for 
new MPAs, and eventually forming a network of MPAs for a given planning area generally follows the coastal resource management planning process followed by local governments in the Philippines (DENR-CMMO, 2003; White et al., 2006b). The process of information gathering, analyzing, planning, implementing, and then monitoring and evaluation is field tested and does promote adaptive management.

It is generally agreed that the MPA planning and implementation processes must be done in concert with the local governments and communities of concern and in coordination with other projects and stakeholders in an area. The protocols for assisting communities and local government with the planning and implementation of MPAs have been tested (White et al., 2006a). Several points, based on field experience, to guide projects to improve MPA effectiveness and in forming MPA networks (CRMP, 2004) are:

1. Most MPAs, once planned and operating, need to strengthen their management body through a community level intervention that helps the management body develop and implement a MPA management plan together with the municipal administration. The MPA plan may ultimately amend the local government ordinance that established the MPA with refined rules.

2. The project will need to identify partners working in the area who are assisting with ICM and MPAs and coordinate work accordingly. Assisting groups should make a strategic plan and agree on objectives that are complementary.

3. Each MPA that will ultimately be part of an effective network requires some level of assistance in its planning and implementation. All successful MPAs in the Philippines have received assistance to help them be sustainable.

MPA networks are not created rapidly but can evolve over time with good planning and management. Strategic interventions required to help the process in the Philippine context include:

- Provision of support for MPA monitoring and evaluation that addresses biophysical and management needs using existing protocols (White et al., 2006a; Uychiaoco et al., 2001);

- Summaries of all relevant data in a geographical (maps) and graphic manner for feedback to communities and for use in planning and education through simple reports and visual means to keep the data useful at the local level;

- Training of local stakeholders to perform the tasks of planning, implementing, monitoring and evaluation using tested protocols (e.g., MPA Report Guide);

- Technical assistance on conflict resolution and other institutional issues;

- Targeted research studies on the effectiveness of MPAs, locating new MPAs, social acceptability of MPAs, oceanography of area, location of fish aggregation areas as deemed relevant for planning and education;

- Mentoring of all targeted MPA management bodies in a systematic manner;

- Sponsoring workshops and informal meetings among MPA managers, management bodies, and other stakeholders to help establish social networks;

- Linking of all existing and future MPA work (data, results, MPA establishment, etc.) with national programs to support MPAs such as the Protected Area and Wildlife Bureau of DENR, the MPA Database, and others. 


\section{Conclusions on Scaling Up to Networks in the Philippines}

An MPA network is primarily a network of people and organizations managing the component MPAs, benefiting from the network and promoting the networks' viability and longevity through shared administrative responsibility and information. Equally important to qualify is that a network of MPAs must interact in an ecologically meaningful manner (e.g., source or sink of larvae and propagating organisms, protection for quality habitat and threatened or endangered species) that enhance fisheries and biodiversity conservation. Thus in the Philippine context, an effective MPA network is composed of individual MPAs that each satisfies the requirements of an effective MPA as highlighted in this article, and the network must have an institutional framework that supports it as an interactive network, not just a group of individual MPAs.

Networks provide an opportunity for those involved in MPA management to learn from each other. Some participants exchange information about resource conditions, best management practices, and shared management issues. Others, such as the Philippine MPA Support Network, hold workshops, organize trainings, and have formal data collection protocols.

The process of scaling up is stimulating the development of formal and informal social and administrative networks to advocate issues, link professionals and citizens with shared concerns, and encourage learning among practitioners facing common concerns. Formal networks that have well-defined membership criteria, a central "node" or administrator, participation requirements, specific communication modes and practices, and other features (Heinz, 2004) are starting to be formed. However, less formal networks that have shared interests or concerns are more common. Philippine MPA managers, for example, are learning from the ecological, planning, or administrative experiences of other managers. Such "communities of practice" constitute important informal learning networks (Eisma-Osorio et al., 2009).

Finally, one of the major constraints to MPA sustainability is long-term financing. In addition to a national Integrated Protected Areas Fund administered by the national government, local area networks are collecting user fees and receiving institutional support from their local municipality or city and the province from Internal Revenue Allotments (budget to local governments from national government). Local government support is also attracting private sector buy-in from tourist resorts, landowners, or others concerned about coastal protection. Valuation studies, research on willingness to pay and user fees, together with cost-benefit analyses of networking arrangements are showing the large potential benefits and mechanisms for collection and management through networking arrangements (World Bank, 2006; Eisma-Osorio et al., 2009).

\section{Note}

1. MPA rating system defined by White et al. $(2004,2006 \mathrm{a})$ is being applied as a tool to monitor and improve MPA management effectiveness. Level 3 implies that the MPA is fully enforced in the short term but not yet institutionalized and sustainable (Levels 4 and 5) (www.coast.ph).

\section{References}

Agrawal, A., and C. C. Gibson. 1999. Enchantment and disenchantment: The role of community in natural resource conservation. World Development 27:629-649. 
Alino, P. M., N. E. Palomar, H. O. Arceo, and A. T. Uychiaoco. 2002. Challenges and opportunities for marine protected area (MPA) management. Proceedings of the 9th International Coral Reef Symposium 2:635-640.

Armada, N., A. T. White, and P. Christie. 2009. Managing fisheries resources in Danajon Bank, Bohol, Phillipines: An ecosystem-based approach. Coastal Management 37:308-330.

Balgos, M. C. 2005. Integrated coastal management and marine protected areas in the Philippines: Concurrent developments. Ocean and Coastal Management 48:972-995.

Berkes, F. 2006. From community-based resource management to complex systems: The scale issue and marine commons. Ecology and Society 1(11):45-60.

Carpenter, K. E., and V. G. Springer. 2005. The center of the center of marine shore fish biodiversity: The Philippine Islands. Environmental Biology of Fishes 72:467-480.

Cash, David W., W. N. Adger, F. Berkes, P. Garden, L. Lebel, P. Olsson, L. Prithchard, and O. Young. 2006. Scale and cross-scale dynamics: Governance and information in a Multilevel World. Ecology and Society 11(2):8-20.

CRMP (Coastal Resource Management Project). 2004. Modeling the Way: Lessons in Developing Capacity for Coastal Management in the Philippines. Special Report (1996-2004). CRMP, Cebu City, Philippines. 111 p.

Christie, P., R. B. Pollnac, E. G. Oracion, A. Sabonsolin, R. Diaz, and D. Pietri. 2009. Back to basics: An empirical study demonstrating the importance of local-level dynamics for the success of tropical marine ecosystem-based management. Coastal Management 37:349-373.

Christie P., A. T. White, and E. Deguit. 2002. Starting point or solution? Community-based marine protected areas in the Philippines. Journal of Environmental Management 66:441-454.

Christie, P., D. Buhat, L. R. Garces, and A. T. White. 2003. The challenges and rewards of community-based coastal resources management: San Salvador Island, Philippines. In Contested Nature-Promoting international biodiversity conservation with social justice in the twenty-first century, eds. S. R. Brechin, P. R. Wilshusen, C. L. Fortwangler, and P. C. West, 231-249. Albany, NY: SUNY Press.

Davis, A., and C. Bailey. 1996. Common in custom, uncommon in advantage: Common property, local elite, and alternative approaches to fisheries management. Society and Natural Resources 9:251-265.

DENR-CMMO (Department of Environment and Natural Resources-Coastal and Marine Management Office). 2003. Monitoring and Evaluating Municipal/City Plans and Programs for Coastal Resource Management. Coastal Resource Management Project of Department of Environment and Natural Resources, Cebu City, Philippines. 93 p.

Eisma, R.-L., P. Christie, and M. J. Hershman. 2005. Legal issues affecting sustainability of integrated coastal management in the Philippines. Ocean and Coastal Management 48:336359.

Eisma-Osorio, R.-L., R. C. Amolo, A. P. Maypa, A. T. White, and P. Christie. 2009. Scaling up local government initiatives toward ecosystem-based fisheries management in Southeast Cebu Island, Philippines. Coastal Management 37:291-307.

Evans, R. D., G. R. Russ, and J. P. Kritzer. 2008. Batch fecundity of Lutjanus carponotatus (Lutjanidae) and implication of no-take marine reserves on the Great Barrier Reef Marine Park, Queensland, Australia. Coral Reefs 27:179-189.

Folke, C., L. Prithchard, Jr., F. Berkes, J. Colding, and U. Svedin. 1998. The Problem of Fit Between Ecosystems and Institutions. International Human Dimensions Programme [IHDP] Working Paper 2, Human Dimensions Programme on Environmental Change, Bonn, Germany.

Heinz, J., Center for Science, Economics and the Environment. 2004. Innovation by Design: Improving Learning Networks in Coastal Management. Washington, DC: John Heinz Center.

Imperial, M. T., and T. Yandle. 2005. Taking institutions seriously: Using the IAD framework to analyze fisheries policy. Society and Natural Resources 18:493-509.

Indab, J. D., and P. B. Suarez-Aspilla. 2004. Community-based marine protected areas in the Bohol (Mindanao) Sea, Philippines. NAGA, WorldFish Center Quarterly 27(1 \& 2):4-8. 
IUCN World Commission on Protected Areas (IUCN-WCPA). 2008. Establishing Resilient Marine Protected Area Networks: Making It Happen. Washington, DC: IUCN-WCPA, National Oceanic and Atmospheric Administration and the Nature Conservancy. $118 \mathrm{p}$.

Jones, P. J. S. 2007. Point-of-view: Arguments for conventional fisheries management and against no-take marine protected areas: Only half of the story? Reviews in Fish Biology and Fisheries 17:31-43.

Lavides, M. N., and F. Tiburcio. 2002. Building a national community of local coastal resource managers in the Philippines. In Proceedings of the 2nd National Workshop on the Formulation of a National Fish Sanctuary Strategy, eds. W. L. Campos, P. D. Beldia II, and P. M. Alino, 90-99. Visayas, Iloilo: University of the Philippines. 242 p.

Lowry, K., A. White, and C. Courtney. 2005. National and local agency roles in integrated coastal management in the Philippines. Ocean and Coastal Management 48:314-335.

Ong, P. S., L. E. Afuang, and R. G. Roselle-Ambal. 2002. Philippine biodiversity conservation priorities: A second iteration of the national biodiversity strategy and action plan. Quezon City, Philippines: Department of Environment and Natural Resources-Protected Area Wildlife Bureau, Conservation International Philippines, University of the Philippines-Center for Integrative and Development Studies and Foundation for Philippine Environment. 113 p.

Palumbi, S. R. 2004. Marine reserves and ocean neighborhoods: The spatial scale of marine populations and their management. Annual Review of Environment and Resources 29:31-68.

PhilReefs (Coral Reef Information Network of the Philippines). 2008. Reefs Through Time 2008: Initiating the State of the Coasts Reports. Coral Reef Information Network of the Philippines (PhilReefs), MPA Support Network, Marine Environment \& Resources Foundation, Inc. and the Marine Science Institute, University of the Philippines, Diliman, Quezon City. 152 p.

Pollnac, R. B., and R. S. Pomeroy. 2005. Factors affecting the long-term sustainability of integrated coastal management projects in the Philippines and Indonesia. Ocean and Coastal Management 48:233-251.

Pomeroy, R. S., E. G. Oracion, R. B. Pollnac, and D. A. Caballes. 2005. Perceived economic factors influencing the sustainability of integrated coastal management projects in the Philippines. Ocean and Coastal Management 48:360-377.

Roberts, C. M., G. Branch, R. H. Bustamante, J. C. Castilla, J. Dugan, B. S. Halpern, K. D. Lafferty, H. Leslie, J. Lubchenco, D. McArdle, M. Ruckelshaus, and R. R. Warner. (2003). Application of ecological criteria in selecting marine reserves and developing reserve networks. Ecological Applications 13(1): Supplement, S215-S228.

Russ, G. R., A. C. Alcala, A. P. Maypa, H. P. Calumpong, and A. T. White. 2004. Marine reserve benefits local fishers. Ecological Applications 14:597-606.

Tabara, J. D., and C. Pahl-Wostl. 2007. Sustainability learning in natural resource use and management. Ecology and Society 12:3-18.

United Nations Environment Program (UNEP) and World Conservation Monitoring Centre (WCMC). 2008. Establishing National and Regional Networks of MPAs-A Review of Progress with Lessons Learned. UNEP and WCMC, draft report. $106 \mathrm{p}$.

Uychiaoco, A. J., S. J. Green, M. T. dela Cruz, P. A. Gaite, H. O. Arceo, P. M. Alino, and A. T. White. 2001. Coral reef monitoring for management. Philippines: Marine Science Institute-University of the Philippines and other institutions. $110 \mathrm{p}$.

WCPA/IUCN. 2007. Establishing Networks of Marine Protected Areas: A Guide for Developing National and Regional Capacity for Building MPA Networks. Full Technical Report, IUCN.

WFC (World Fish Center). 2007. Coral Reef MPAs of East Asia and Micronesia. World Fish Center (REEFBASE Project), Sea Around Us Project, Japan Wildlife Research Center. CD.

White, A. T., R. L. Eisma-Osorio, and S. J. Green. 2005. Integrated coastal management and marine protected areas: Complementarity in the Philippines. Ocean and Coastal Management 48:948-971.

White, A. T., A. Salamanca, and C. A. Courtney. 2002. Experience with marine protected area planning and management in the Philippines. Coastal Management 30:1-26. 
White, A. T., A. T. Meneses, and M. F. Ovenden. 2004. Management rating system for marine protected areas: An important tool to improve management. In In turbulent seas: The status of Philippine marine fisheries, DA-BFAR, 226-231. Cebu City, Philippines: Coastal Resource Management Project. 378 p.

White, A. T., P. M Alino, and A. T. Meneses. 2006a. Creating and managing marine protected areas in the Philippines. Cebu City, Philippines: Fisheries Improved for Sustainable Harvest Project, Coastal Conservation and Education Foundation, Inc. and University of the Philippines Marine Science Institute. $83 \mathrm{p}$.

White, A. T., E. Deguit, W. Jatulan, and L. Eisma-Osorio. 2006b. Integrated coastal management in Philippines local governance: Evolution and benefits. Coastal Management 34:287-302.

World Bank. 2006. Scaling up Marine Management: The Role of Marine Protected Areas. Report no. 36635-GLB. Environment Department/Sustainable Development Network. World Bank, Washington DC, USA. 100 p.

Yeung, H. 2000. Organizing 'the firm' in industrial geography: Networks, institutions, and regional development. Progress in Human Geography 24(2):301-315. 